\title{
Using Severe Plastic Deformation to Fabricate Strong Metal Matrix Composites
}

\author{
Megumi Kawasaki ${ }^{a, b *}$, Terence G. Langdon ${ }^{c, d}$ \\ ${ }^{a}$ Division of Materials Science and Engineering, Hanyang University, Seoul 133-791, South Korea \\ ${ }^{b}$ School of Mechanical, Industrial and Manufacturing Engineering, Oregon State University, Corvallis, OR, \\ 97331-6001, USA \\ ${ }^{c}$ Departments of Aerospace \& Mechanical Engineering and Materials Science, University of Southern \\ California, Los Angeles, CA 90089-1453, USA \\ ${ }^{d}$ Materials Research Group, Faculty of Engineering and the Environment, University of Southampton, \\ Southampton SO17 1BJ, U.K.
}

Received: February 23, 2017; Revised: August 05, 2017; Accepted: September 19, 2017

\begin{abstract}
The processing of bulk metals through the application of severe plastic deformation leads to significant grain refinement and a consequent strengthening of the material. High-pressure torsion (HPT) generally refers to the processing of disk samples and this technique is especially effective in producing extremely small grains. Recently, new experiments were conducted in which disks of two different alloys, based on aluminum and magnesium, were stacked together and then processed by HPT for up to 20 turns at room temperature. Analysis after processing revealed the formation of a multi-layered structure in the central region of the disks but with a true nanoscale microstructure containing different types of intermetallic compounds within an Al matrix leading to the formation of metal matrix nanocomposites at the disk edges. Measurements showed a lowering of density at the disk edges, thereby confirming the potential for using HPT to fabricate materials with exceptionally high strength-to-weight ratios.
\end{abstract}

Keywords: Al-Mg, diffusion bonding, hardness, high-pressure torsion, metal-matrix nanocomposite

\section{Introduction}

True nanostructures in bulk materials are difficult to produce using established engineering techniques, especially when considering the practical and societal needs of materials selection. Light-weight metals of aluminum and magnesium are conventional materials having excellent mechanical properties and with good strength-to-weight ratios in the finished products so that these metals are widely used for structural applications in the automotive, aerospace and electronic industries.

An earlier report demonstrated an increase in the strength limit of an aerospace-grade Al-7075 alloy through the application of high-pressure torsion (HPT) while maintaining appropriate formability. ${ }^{1}$ Processing by HPT is a most promising severe plastic deformation (SPD) technique producing true nanometer grains leading to and providing an excellent potential for achieving high hardness in most bulk metals. ${ }^{2}$ In recent years, because of the introduction of intense plastic strain during processing, HPT has also been applied for the consolidation of metallic powders ${ }^{3-10}$ and the bonding of machining chips ${ }^{11,12}$.

There is, however, a saturation in the improved mechanical properties by grain refinement and further superior properties are not easy to obtain by processing directly on the alloy unless a subsequent SPD processing technique is applied on the processed material. ${ }^{13}$ Utilizing the conventional processing of HPT, it is anticipated that it may be possible

*e-mail: megumi.kawasaki@oregonstate.edu to produce a new metal system from a combination of simple dissimilar metal solids and, in addition, the metal system may exhibit superior mechanical properties which are above the upper limit of the properties that may be achieved by these individual base metals through SPD. Thus, this report was initiated to suggest an alternative method for fabricating a high performance material by bonding dissimilar metals for synthesizing new metal systems through the application of HPT.

Accordingly, a new approach of applying conventional HPT processing was studied for the formation of an Al$\mathrm{Mg}$ hybrid system and ultimately attaining a metal matrix nanocomposite (MMNC) from separate $\mathrm{Al}$ and $\mathrm{Mg}$ disks at room temperature through diffusion bonding of $\mathrm{Al}$ and $\mathrm{Mg}$ alloys at room temperature (RT). The present study shows the unique microstructure and hardness distributions and also provides a detailed analysis of the strengthening mechanism for the Al-Mg hybrid system formed by HPT. The results demonstrate the feasibility of HPT processing in the preparation of new alloy systems and a wide range of MMNCs exhibiting exceptionally high strength-to-weight ratios.

\section{Processing of the Al-Mg system}

The experiments were conducted using a commercial purity Al-1050 aluminum alloy and a ZK60 magnesium alloy where these materials were received as extruded bars having diameters of $\sim 10 \mathrm{~mm}$. These bars were cut into billets with lengths of $\sim 65 \mathrm{~mm}$ and a number of disks was sliced 
from the billets and polished to achieve uniform thicknesses of $\sim 0.83 \mathrm{~mm}$.

The direct bonding of the $\mathrm{Al}$ and $\mathrm{Mg}$ disks was performed through conventional HPT processing at RT following the general processing procedure described earlier ${ }^{14}$ using a quasi-constrained facility ${ }^{15,16}$ under a hydraulic pressure of $6.0 \mathrm{GPa}$ for 1, 5, 10 and 20 turns at a rotational speed of $1 \mathrm{rpm}$. In particular, separate disks of the $\mathrm{Al}$ and $\mathrm{Mg}$ alloys were placed in the depression on the lower anvil in the order of $\mathrm{Al} / \mathrm{Mg} / \mathrm{Al}$ where the $\mathrm{Mg}$ disk was positioned between the two $\mathrm{Al}$ disks but without using any glue or metal brushing treatment. A schematic illustration of the piled up disks between the conventional HPT anvil set-up is shown in Fig. 1(a)..$^{17,18}$

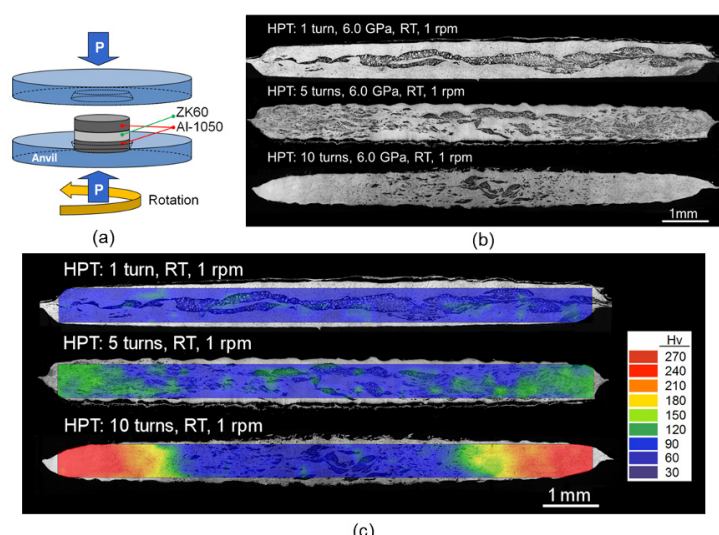

Figure 1. (a) Schematic illustration of the sample set-up for HPT processing and (b) an overview of the microstructure and (c) colorcoded hardness contour maps taken at the vertical cross-sections along the disk diameters after HPT for 1, 5 and 10 turns, respectively. ${ }^{17-19}$

Overviews of the microstructures are shown in Fig. 1(b $)^{17,18}$ at the cross-sections of the disks by optical microscopy (OM) after HPT for 1, 5 and 10 turns from the top, respectively, where the bright regions denote the Al-rich phase and the dark regions correspond to the $\mathrm{Mg}$-rich phase in these micrographs. As is apparent in Fig. 1(b), a multi-layered structure with fragmented Mg layers with thicknesses of $\sim 200 \mu \mathrm{m}$ was visible without any segregation throughout the disk after 1 turn. A similar microstructure consisting of multi-layers of the Al and $\mathrm{Mg}$ phases was observed at the central regions at $r<2.0$ and $<1.0 \mathrm{~mm}$ of the disks after 5 and 10 turns, respectively, where $r$ denotes the radius of the HPT disk. However, the disk edge at $r>2.5 \mathrm{~mm}$ after 5 turns demonstrated a unique microstructure involving a homogeneous distribution of very fine $\mathrm{Mg}$ phases with thicknesses of $\sim 5-10 \mu \mathrm{m}$ to even a true nano-scale of $\sim 100-500 \mathrm{~nm}$ within the $\mathrm{Al}$ matrix. Moreover, there was no evidence of visible $\mathrm{Mg}$ phases at the disk edge at $\sim 3<r<5 \mathrm{~mm}$ after 10 turns.

Figure 1(c) shows the distribution of Vickers microhardness over the vertical cross-sections of the processed Al-Mg disks after 1-10 turns. In practice, the measured hardness values were visualized by constructing color-coded hardness contour maps for the disks after 1, 5 and 10 HPT turns from the top, respectively, where the detailed hardness values are indicated in the key on the right. These maps are demonstrated on representative locations of the OM micrographs shown in Fig. 1(b). For reference, the Vickers microhardness, Hv, were $\sim 65$ for the Al-1050 alloy ${ }^{20}$ and $\sim 110$ for the ZK60 alloy ${ }^{21}$ when processed by HPT for 5 turns and thus these Hv values reached a saturation level across the disk diameters due to sufficient torsional straining. ${ }^{22,23} \mathrm{~A}$ very first demonstration for the construction of the color-coded hardness maps were shown by using a set of Vickers microhardness values on disk surfaces of an HPT-processed pure Al. ${ }^{14}$

The overall cross-section after HPT for 1 turn shows an average microhardness value of $\sim 70$ which is similar to the value for the base material of the $\mathrm{Al}$ alloy processed for 5 HPT turns. This low hardness value remains constant at the disk centers at $r<3.0 \mathrm{~mm}$ and $<2.5 \mathrm{~mm}$ of the Al-Mg disks after 5 and 10 HPT turns, respectively. However, high hardness with a maximum of $\mathrm{Hv} \approx 130$ was observed at the periphery of the disk after 5 turns where the fine $\mathrm{Mg}$ phase was homogeneously distributed within the Al matrix. Moreover, there is a significant increase in $\mathrm{Hv}$ after 10 turns where a maximum hardness of $\sim 270$ was achieved at the peripheral region at $r>3.0 \mathrm{~mm}$. These high hardness values measured in the Al-Mg system after HPT are much higher than the base alloys of $\mathrm{Al}$ and Mg after HPT and a detailed microstructural analysis was followed in order to understand the hardening mechanism of this unique $\mathrm{Al}-\mathrm{Mg}$ system produced by HPT processing.

\section{Formation of MMNCs and the hardening mechanism}

The detailed microstructure was analyzed at the disk edges after 5 and 10 turns and these results are shown in Figs 2 and 3, respectively. A micrograph taken by transmission electron microscopy (TEM) is shown in Fig. 2(a) for the disk edge after $5 \mathrm{HPT}$ turns ${ }^{17-19}$ where the Al matrix phase consists of a layered microstructure with thicknesses of $\sim 90-120 \mathrm{~nm}$ and the average spatial grain size, $d$, in the $\mathrm{Al}$ matrix phase was $\sim 190 \mathrm{~nm}$. As indicated, there is a single visible $\mathrm{Mg}$ phase in the TEM micrograph and it has a homogeneous bonding interface with the $\mathrm{Al}$ matrix without any visible voids. Moreover, within the $\mathrm{Al}$ matrix phase there were several very thin layers with an average thickness of $\sim 20$ $\mathrm{nm}$ as indicated by the white arrows.

Close examination was conducted on the thin layers through quantitative chemical analysis by point scanning at the two different locations on a thin layer and a location out of the thin layer and by line scanning at the location across the thin layer where these examined locations are marked in blue points and a white line, respectively, in Fig. 2(b) and the 


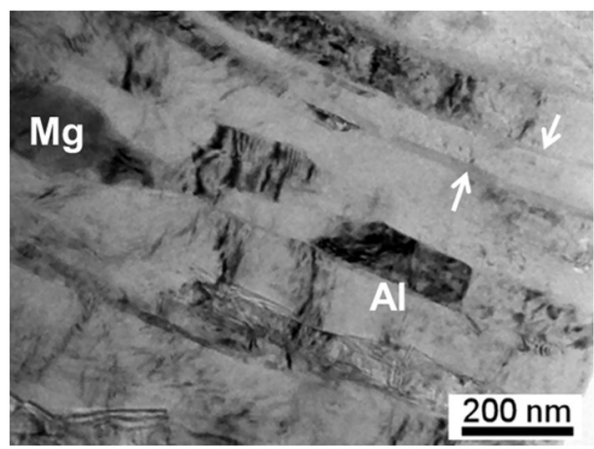

(a)

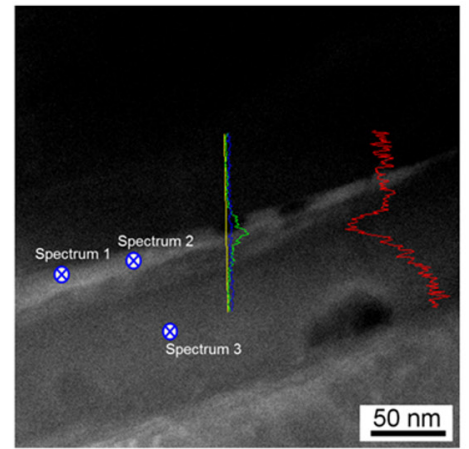

(b)

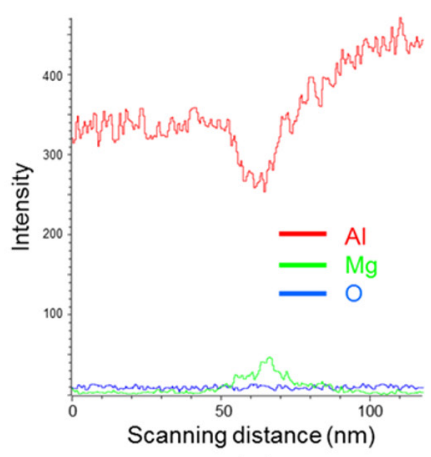

(c)

Figure 2. TEM micrographs taken at the disk edges after HPT for 5 turns showing (a) a bright-field image of a layered microstructure, (b) a dark-field image taken at the disk edge after HPT for 5 turns with the EDS scanning line marked vertically and (c) the scanning result shown in (b) as a plot of the relative intensities with respect to the scanning distance for $\mathrm{O}, \mathrm{Mg}$ and $\mathrm{Al}$ marked in blue, green and red, respectively. ${ }^{17}$

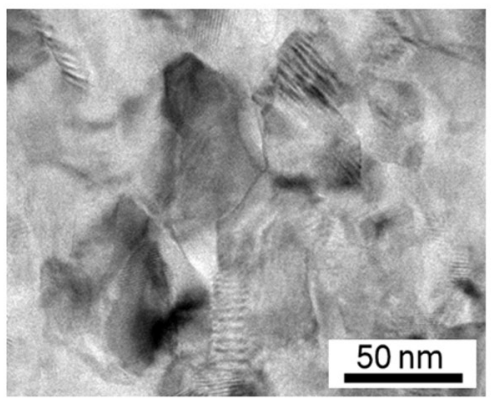

(a)

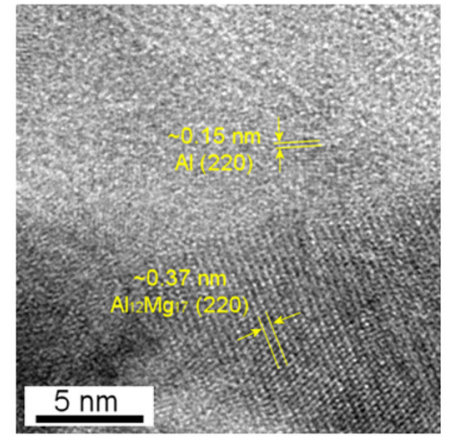

(c)
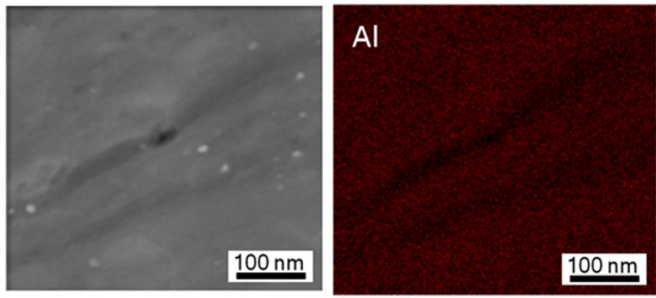

(b)

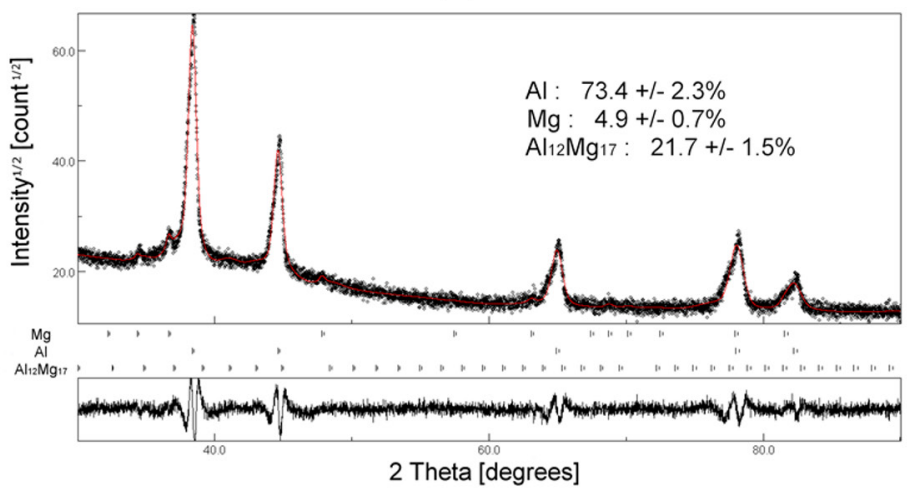

(d)

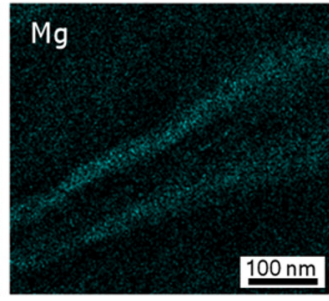

$\mathrm{nm}$

Mg: $4.9+1-0.7 \%$

$\mathrm{Al}_{12} \mathrm{Mg}_{17}: \quad 21.7+/-1.5 \%$

[degrees]

Figure 3. TEM micrographs with (a) a bright-field image, (b) a dark-field image and the corresponding compositional maps of $\mathrm{Al}$ and $\mathrm{Mg}$ and (c) a high resolution image and (d) the XRD pattern in black and the simulated line profile in red for the edge of the Al-Mg system after HPT for 10 turns. $^{17}$

result of the line scanning is shown in Fig. 2(c) for elements of $\mathrm{Al}, \mathrm{Mg}$ and $\mathrm{O}$ marked in different colors. ${ }^{17}$

The point scanning and the line profile revealed that the thin layers are composed of $66-78$ at. $\% \mathrm{Al}$ and $24-30$ at. $\% \mathrm{Mg}$, thereby suggesting an intermetallic compound of $\beta$ - $\mathrm{Al}_{3} \mathrm{Mg}_{2}$ which has a low density of $\sim 2.25 \mathrm{~g} \mathrm{~cm}^{-3} \cdot{ }^{24}$ Since the thin layers existed irregularly in the $\mathrm{Al}$ matrix as seen in Fig. 2(a), the HPT processing demonstrated the formation of an intermetallic-based MMNC in the Al-Mg system at the disk edge after 5 turns. It is anticipated that $\beta-\mathrm{Al}_{3} \mathrm{Mg}_{2}$ provides an excellent potential for reinforcing the MMNC by improving the hardness and strength as was shown in Fig. 1(c). The point analysis also demonstrated that the $\mathrm{Al}$ matrix contains $\sim 0.21 \mathrm{wt} . \% \mathrm{Mg}$ which is higher than $\sim 0.05$ wt.\% Mg in the initial Al-1050 alloy. However, it is lower than the maximum solubility of $\sim 1.4 \mathrm{wt} . \% \mathrm{Mg}$ in $\mathrm{Al}$ at RT, thereby suggesting no formation of a supersaturated solid solution in the $\mathrm{Al}-\mathrm{Mg}$ system at the disk edge after $5 \mathrm{HPT}$ turns.

Detailed microstructural characterization was conducted on the Al-Mg disk after 10 HPT turns using a high resolution TEM analysis, a chemical analysis by energy-dispersive $\mathrm{X}$-ray spectroscopy (EDS) in a scanning transmission 
electron microscope (STEM) and an X-ray diffraction (XRD) analysis using Materials Analysis Using Diffraction (MAUD) software. It should be noted that there was no evidence of an Mg-rich phase at the disk edge after HPT for 10 turns.

A TEM micrograph in Fig. 3(a) showed a true nanostructure with a spatial grain size of $\sim 90 \mathrm{~nm}$ at the disk edge. ${ }^{17} \mathrm{~A}$ detailed chemical analysis observed $\sim 61$ at.\% $\mathrm{Al}$ and $~ 39$ at. $\%$ $\mathrm{Mg}$ for an irregularly-distributed intermetallic compound, $\beta-\mathrm{Al}_{3} \mathrm{Mg}_{2}$, as a form of thin layers of $\sim 30 \mathrm{~nm}$ in the Al matrix as shown in Fig. 3(b). In addition, a high resolution TEM analysis and an XRD analysis as shown in Fig. 3(c) and (d), respectively, revealed the formation of another intermetallic compound of $\gamma-\mathrm{Al}_{12} \mathrm{Mg}_{17}$ in the $\mathrm{Al}$ matrix, while the very small amount of $\beta-\mathrm{Al}_{3} \mathrm{Mg}_{2}$ with $<5$ vol. $\%$ was not detected in the X-ray analysis. It should be noted that the additional point analysis at the Al-rich phase revealed a supersaturated solid solution state with an $\mathrm{Mg}$ content of $>4.7$ at. $\%$ at the disk edge after 10 turns. $^{17}$

It is emphasized that the rapid diffusivity of $\mathrm{Mg}$ atoms into the Al matrix is a key process for the diffusion bonding of $\mathrm{Al}$ and $\mathrm{Mg}$ and for the formation of intermetallic compounds through HPT. ${ }^{18}$ Several recent studies demonstrated experimental evidence for enhanced atomic diffusion in nanostructured materials processed by $\mathrm{ECAP}^{25}$ and $\mathrm{HPT}^{17,26}$. The fast diffusivity in these processed materials may be attributed to the processing conditions including severe hydraulic pressure $^{17}$ and torsional stress ${ }^{26}$ during HPT processing and the high population of lattice defects produced in the nanostructure. ${ }^{25} \mathrm{~A}$ recent review describes the significance of the fast atomic mobility during SPD by recognizing the significant increase in the vacancy concentration through SPD processing. ${ }^{27}$

The major strengthening mechanisms for achieving exceptional hardness were evaluated for the intermetallic-based MMNC synthesized by HPT for 10 turns under $6.0 \mathrm{GPa}$ at RT. Thus, it is assumed to achieve the Vickers microhardness values by the sum of the separate strengthening mechanisms expressed by Hall-Petch strengthening due to significant grain refinement, solid solution strengthening because of the high content of $\mathrm{Mg}$ atoms leading to the increased frictional stress within the crystal lattices, and precipitation hardening by the thin layers of the $\beta-\mathrm{Al}_{3} \mathrm{Mg}_{2}$ intermetallic compound. ${ }^{28}$

The total achievable hardness was estimated with increasing $\mathrm{Mg}$ content in an $\mathrm{Al}$ solid solution matrix in the disk after HPT for 10 turns and the estimation is shown in Fig. $4 .{ }^{17}$ Although there was an increasing contribution of solution strengthening with increasing $\mathrm{Mg}$ contents in the Al matrix, Hall-Petch strengthening by grain refinement was anticipated to provide the highest contribution to the total hardness where precipitation hardening was almost negligible due to the very small volume of intermetallic compounds in the form of thin layers in the synthesized MMNC after 10 turns. This estimate was in excellent agreement with the experimental values of hardness in the synthesized Al-Mg alloy after HPT, thereby confirming the simultaneous occurrence of these separate strengthening mechanisms. Moreover, the exceptional hardness was also a consequence of the low processing temperature and the short operating time which prevents the occurrence of any significant microstructural recovery. Consequently, the synthesis of the MMNC may provide the possibility of improving the upper limit on the maximum hardness value in the hybrid Al-Mg system through HPT processing.

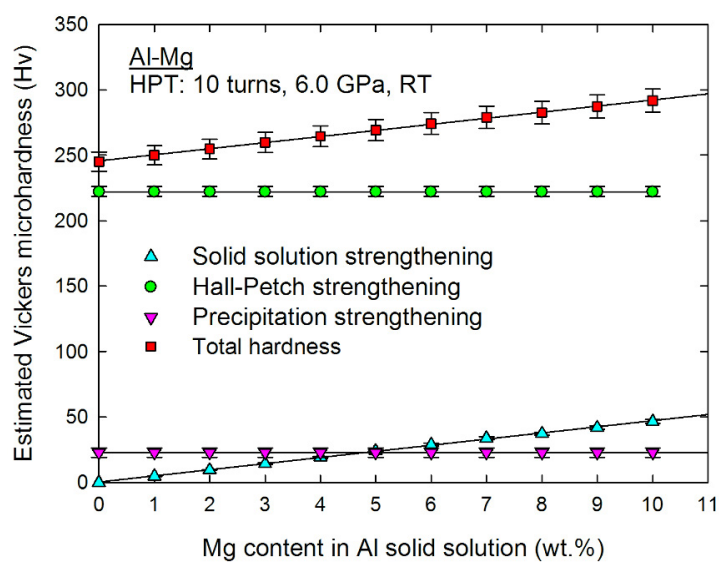

Figure 4. Estimated Vickers microhardness values with increasing $\mathrm{Mg}$ content in $\mathrm{Al}$ solid solutions in the disk after HPT for 10 turns. $^{17}$

\section{Future potential of the HPT technique for synthesized hybrid metals}

There have been extensive investigations for improving the physical and mechanical properties of metals and materials by grain refinement through the application of SPD. In particular, research in the last decade has demonstrated that SPD processing is also feasible for the production of unusual phase transformations and in the introduction of a range of nanostructural features. ${ }^{29,30}$ Therefore, not only improving mechanical properties of separate metal samples but also processing by SPD can be developed for the alternative method of introducing high performance materials through diffusion bonding of dissimilar metals. This may involve the production of MMNCs as demonstrated by the bonding of $\mathrm{Al}$ and Mg alloys through HPT. There are limited numbers of reports to date demonstrating a sold-state reaction in an Al-Cu system through the bonding of semicircular halfdisks of $\mathrm{Al}$ and $\mathrm{Cu}$ through HPT up to 100 turns at ambient temperature $^{31}$, bonding of a set of two disks of separate $\mathrm{Al}$ and $\mathrm{Mg}$ through HPT for up to 20 turns $^{32}$ and a vision of architecturing hybrid metals through HPT by computational modeling ${ }^{33}$.

A very recent report evaluated the upper limitation of achievable hardness when a MMNC in the Al-Mg system was processed by HPT for higher numbers of turns. Thus, the consistent HPT procedure was applied for a set of three $\mathrm{Al}$ and $\mathrm{Mg}$ disks for 20 turns and the Vickers microhardness 


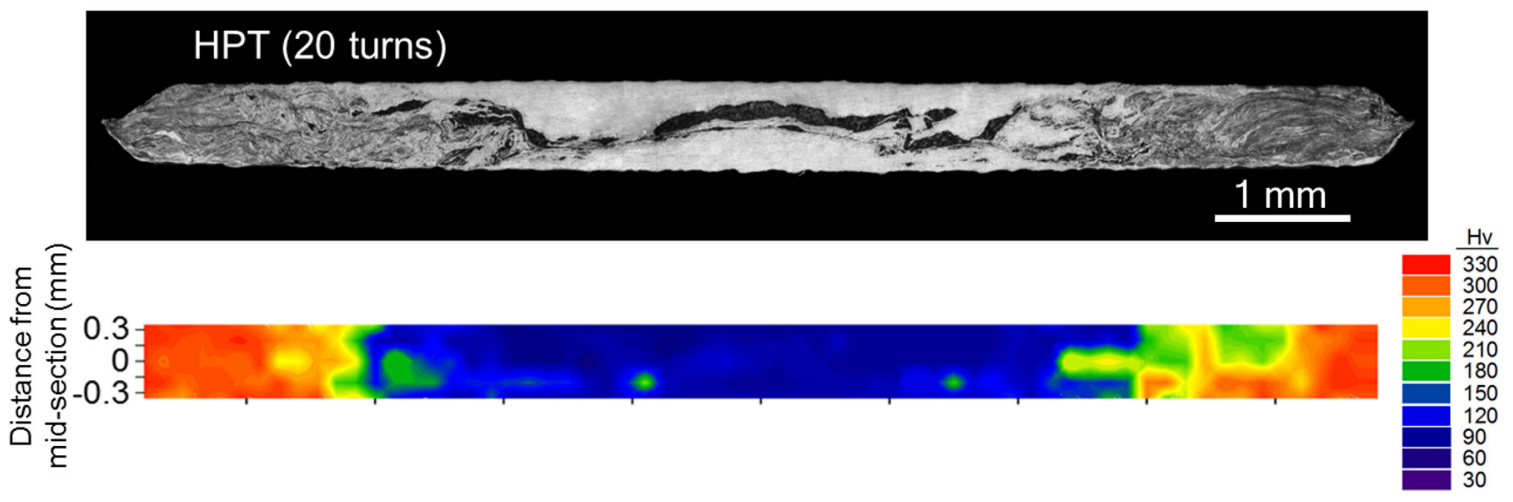

Figure 5. An OM micrograph (upper) and a color-coded contour map of the Vickers microhardness (lower) for the vertical cross-sectional plane of the Al-Mg disks after HPT for 20 turns at room temperature under a pressure of $6.0 \mathrm{GPa}^{34}$

was recorded at the vertical cross-section of the processed disk where the results of the micrograph and the color-coded hardness map are shown in Fig. 5. ${ }^{34}$

It is apparent that the deformed microstructure is reasonably similar to the sample conditions in the Al-Mg system after HPT for 5-10 turns as shown in Fig. 1(b). However, an exceptionally high hardness of $\mathrm{Hv} \approx 330$ was recorded at $r$ $\approx 4.0-5.0 \mathrm{~mm}$ followed by $\mathrm{Hv} \approx 150-240$ at $r \approx 2.5-3.5 \mathrm{~mm}$ while a lower hardness with $\mathrm{Hv} \approx 60$ was observed at the central region of the disk at $r<2.5 \mathrm{~mm}$. The highest hardness of $\mathrm{Hv} \approx 330$ after HPT for 20 turns is significantly higher than the highest value of $\mathrm{Hv} \approx 270$ recorded after 10 turns as shown in Fig. 1(c), thereby demonstrating a potential of a further enhancement in hardness when applying higher straining by HPT.

Considering the future potential of the hybrid materials processed by SPD, it is necessary to apply quantitative analysis and thus it is reasonable to visualize an enhancement in the strength-to-weight ratio of the MMNC synthesized at the disk edges of the Al-Mg system by comparison with the base metals of the $\mathrm{Al}$ and $\mathrm{Mg}$ alloys. Thus, the density was measured at the disk edges consisting of MMNCs of the processed Al-Mg hybrid materials after 5, 10 and 20 HPT turns and the reference materials of the Al-1050 and ZK60 alloys after HPT for 5 turns. The values of density were measured directly from the volume and weight of each sample disk. Applying the measured density and hardness values, the strength-to-weight ratio was estimated for each material and these measured and calculated values are shown in Table 1. It is apparent that the density for the Al-Mg system decreases with increasing HPT turns leading to the concurrent occurrence of diffusion bonding, a reduction in the $\mathrm{Mg}$-rich phases and the introduction of intermetallic compounds. Due to the lowered density, the Al-Mg system after 10 and $20 \mathrm{HPT}$ turns demonstrated an excellent strength-to-weight ratio of $\sim 350$ and $455 \mathrm{MPa} \mathrm{cm} \mathrm{g}^{-1}$, respectively, and these values are significantly higher than the base materials of the $\mathrm{Al}$ and $\mathrm{Mg}$ alloys.
Table 1. The measured density, the maximum Vickers hardness value, and the estimated strength-to-weight ratio for the MMNCs in the Al-Mg system after HPT for 5-20 turns and the reference materials of Al-1050 and ZK60 alloys after HPT for 5 turns.

\begin{tabular}{cccc}
\hline Materials & $\begin{array}{c}\text { Density } \\
\left(\mathrm{g} \mathrm{cm}^{-3}\right)\end{array}$ & $\begin{array}{c}\text { Maximum } \\
\text { hardness } \\
(\mathrm{Hv})\end{array}$ & $\begin{array}{c}\text { Strength-to- } \\
\text { weight ratio } \\
\left(\mathrm{MPa} \mathrm{cm}^{3} \mathrm{~g}^{-1}\right)\end{array}$ \\
\hline $\begin{array}{c}\text { MMNC after } \\
5 \text { HPT turns }\end{array}$ & 2.50 & 130 & 170 \\
MMNC after & 2.48 & 270 & 350 \\
10 HPT turns \\
MMNC after \\
$\begin{array}{c}\text { 20 HPT turns } \\
\text { Al-1050 } \\
\text { alloy after 5 } \\
\text { turns }\end{array}$ & 2.34 & 330 & 455 \\
$\begin{array}{l}\text { ZK 60 alloy } \\
\text { after 5 turns }\end{array}$ & 1.84 & $65^{20}$ & 80 \\
\hline
\end{tabular}

For better visualization of the enhancement in the strength-to-weight ratio in the Al-Mg hybrid system processed by HPT, a toughness-strength diagram reported earlier is shown in Fig. $6^{19}$ where it delineates the range of fracture toughness and strength-to-weight ratio for many metals and materials..$^{35}$ Assuming a general similarity in the trends of plasticity and toughness of materials $\mathrm{s}^{36}$, the experimental results for the processed Al-Mg system forming HPTinduced aluminum MMNCs are now incorporated into the diagram without delineating any upper limits. The border line for the field of the Al MMNCs was applied with the extraordinary strength of the hybrid Al-Mg system after 10 HPT turns where $\mathrm{Mg}$ atoms diffused within the $\mathrm{Al}$ matrix completely by rapid diffusion. It is demonstrated from the plot that the strength-to-weight ratio of the HPT-induced Al MMNCs is anticipated to be much higher than many steels and $\mathrm{Ti}$ alloys and it may even be similar to some strong engineering polymeric composites. This evaluation confirms the excellent potential for using HPT processing to fabricate materials with exceptionally high strength-to-weight ratios. 


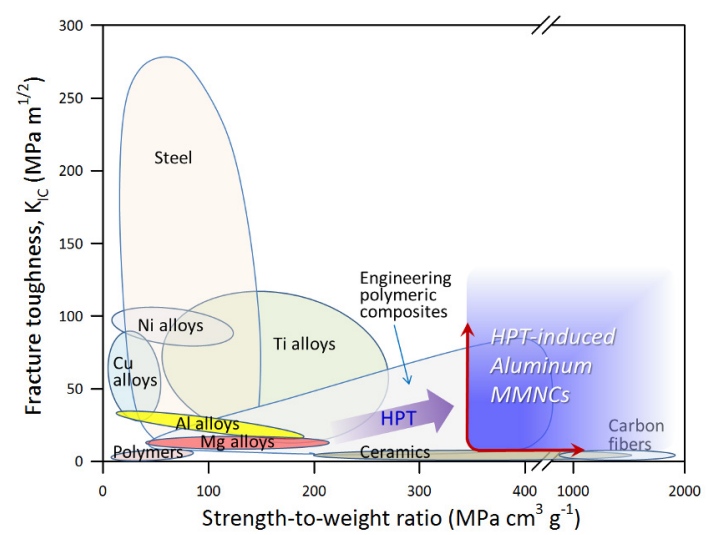

Figure 6. The range of fracture toughness and strength-to-weight ratio for many metals and materials ${ }^{35}$ where the synthesized $\mathrm{Al}-\mathrm{Mg}$ system after HPT is incorporated as the region of HPT-induced aluminum MMNC without delineating any upper limits. ${ }^{19}$

Finally, the HPT processing is feasible to form a gradienttype microstructure ${ }^{37-39}$ or a heterogeneous nanostructure ${ }^{40}$ in terms of grain size and composition ${ }^{(17-19.41)}$ during the formation of new alloy systems and synthesis of MMNCs as was seen in the radial direction from the centers of the HPT disks in Fig. 1(b) and Fig. 5. This type of new material organization is defined as a heterogeneous architecture materia ${ }^{42}$ that is a new category of structure in engineering materials and it is expected to lead to a significant potential for exhibiting excellent mechanical properties.

\section{Summary and conclusions}

1. Conventional HPT processing was applied successfully for the synthesis of a hybrid Al-Mg alloy system having a unique microstructural distribution within the disk through the diffusion bonding of separate $\mathrm{Al}$ and $\mathrm{Mg}$ alloy disks. A unique microstructure was observed with an Al-Mg multi-layered structure at the disk center and with different types of intermetallicbased MMNCs at the disk edges after processing through 5-10 turns.

2. The exceptional hardness in the MMNC at the Al-Mg disk edge was verified as a consequence of Hall-Petch strengthening providing the highest contribution whereas strengthening by solid solution and precipitation contributed simultaneously with relatively minor contributions.

3. The synthesized MMNCs in the Al-Mg hybrid system after HPT demonstrated lower density with increasing hardness when processing by higher numbers of HPT turns, thus exhibiting an excellent potential for HPT processing to fabricate new materials with exceptionally high strength-to-weight ratios.

\section{Acknowledgements}

This work was supported by the NRF Korea funded by MoE under Grant No. NRF-2016R1A6A1A03013422 and by MSIP under Grant No. NRF-2016K1A4A3914691 (MK) and the European Research Council under ERC Grant Agreement No. 267464-SPDMETALS (TGL).

\section{References}

1. Liddicoat PV, Liao XZ, Zhao YH, Zhu YT, Murashkin MY, Lavernia EJ, et al. Nanostructural hierarchy increases the strength of aluminium alloys. Nature Communications. 2010;1:63.

2. Zhilyaev AP, Langdon TG. Using high-pressure torsion for metal processing: Fundamentals and applications. Progress in Materials Science. 2008;53(6):893-979.

3. Korznikov AV, Safarov IM, Laptionok DV, Valiev RZ. Structure and properties of superfine-grained iron compacted out of ultradisperse powder. Acta Metallurgica et Materialia. 1991;39(12):3193-3197.

4. Stolyarov VV, Zhu YT, Lowe TC, Islamgaliev RK, Valiev RZ. Processing nanocrystalline Ti and its nanocomposites from micrometer-sized Ti powder using high pressure torsion. Materials Science and Engineering: A. 2000;282(1-2):78-85.

5. Edalati K, Horita Z, Fujiwara H, Ameyama K. Cold consolidation of ball-milled titanium powders using high-pressure torsion. Metallurgical and Materials Transactions A. 2010;41(13):33083317.

6. Ashida M, Horita Z, Kita T, Kato A. Production of $\mathrm{Al} / \mathrm{Al}_{2} \mathrm{O}_{3}$ nanocomposites through consolidation by high-pressure torsion. Materials Transactions. 2012;53(1):13-16.

7. Cubero-Sesin JM, Horita Z. Powder consolidation of Al-10 $\mathrm{wt} \% \mathrm{Fe}$ alloy by high-pressure torsion. Materials Science and Engineering: A. 2012;558:462-471.

8. Edalati K, Toh S, Iwaoka H, Horita Z. Microstructural characteristics of tungsten-base nanocomposites produced from micropowders by high-pressure torsion. Acta Materialia. 2012;60(9):3885-3893.

9. Edalati K, Daio T, Horita Z, Kishida K, Inui H. Evolution of lattice defects, disodered/ordered phase transformations and mechanical properties in $\mathrm{Ni}-\mathrm{Al}-\mathrm{Ti}$ intermetallics by high-pressure torsion. Journal of Alloys and Compounds. 2013;563:221-228.

10. Zhilyaev AP, Ringot G, Huang Y, Cabrera JM, Langdon TG. Mechanical behavior and microstructural properties of titanium powder consolidated by high-pressure torsion. Materials Science and Engineering: A. 2017;688:498-504.

11. Zhilyaev AP, Gimazov AA, Raab GI, Langdon TG. Using high-pressure torsion for the cold-consolidation of copper chips produced by machining. Materials Science and Engineering: A. 2008;486(1-2):123-126.

12. Edalati K, Yokoyama Y, Horita Z. High-pressure torsion of machining chips and bulk discs of amorphous $\mathrm{Zr}_{60} \mathrm{Cu}_{30} \mathrm{Al}_{10} \mathrm{Ni}_{10}$. Materials Transactions. 2010;51(1):23-26. 
13. Sabbaghianrad S, Langdon TG. A critical evaluation of the processing of an aluminum 7075 alloy using a combination of ECAP and HPT. Materials Science and Engineering: A. 2014;596:52-58

14. Kawasaki M, Langdon TG. The significance of strain reversals during processing by high-pressure torsion. Materials Science and Engineering: A. 2008;498(1-2):341-348.

15. Figueiredo RB, Cetlin PR, Langdon TG. Using finite element modeling to examine the flow processes in quasi-constrained high-pressure torsion. Materials Science and Engineering: $A$. 2011;528(28):8198-8204.

16. Figueiredo RB, Pereira PHR, Aguilar MTP, Cetlin PR, Langdon TG. Using finite element modeling to examine the temperature distribution in quasi-constrained high-pressure torsion. Acta Materialia. 2012;60(6-7):3190-3198.

17. Ahn B, Zhilyaev AP, Lee HJ, Kawasaki M, Langdon TG. Rapid synthesis of an extra hard metal matrix nanocomposite at ambient temperature. Materials Science and Engineering: A. 2015;635:109-117.

18. Kawasaki M, Ahn B, Lee HJ, Zhilyaev AP, Langdon TG. Using high-pressure torsion to process an aluminum-magnesium nanocomposite through diffusion bonding. Journal of Materials Research. 2016;31(1):88-99.

19. Ahn B, Lee HJ, Choi IC, Kawasaki M, Jang JI, Langdon TG. Micro-mechanical behavior of an exceptionally strong metal matrix nanocomposite processed by high-pressure torsion. Advanced Engineering Materials. 2016;18(6):1001-1008.

20. Kawasaki M, Alhajeri SN, Xu C, Langdon TG. The development of hardness homogeneity in pure aluminum and aluminum alloy disks processed by high-pressure torsion. Materials Science and Engineering: A. 2011;529:345-351.

21. Lee HJ, Lee SK, Jung KH, Lee GA, Ahn B, Kawasaki M, et al. Evolution in hardness and texture of a ZK60A magnesium alloy processed by high-pressure torsion. Materials Science and Engineering: A. 2015;630:90-98.

22. Zhilyaev AP, Nurislamova GV, Kim BK, Baró MD, Szpunar JA, Langdon TG. Experimental parameters influencing grain refinement and microstructural evolution during high-pressure torsion. Acta Materialia. 2003;51(3):753-765.

23. Zhilyaev AP, Lee S, Nurislamova GV, Valiev RZ, Langdon TG. Microhardness and microstructural evolution in pure nickel during high-pressure torsion. Scripta Materialia. 2001;44:27532758 .

24. Samson $\mathrm{S}$. The crystal structure of the phase $\beta \mathrm{Mg}_{2} \mathrm{Al}_{3}$ Acta Crystallographica. 1965;19:401-413.

25. Divinski SV, Reglitz G, Rösner H, Estrin Y, Wilde G. Ultra-fast diffusion channels in pure Ni severely deformed by equal-channel angular pressing. Acta Materialia. 2011;59(5):1974-1985.

26. Lee DH, Choi IC, Seok MY, He J, Lu Z, Suh JY, et al. Nanomechanical behavior and structural stability of a nanocrystalline $\mathrm{CoCrFeNiMn}$ high-entropy alloy processed by high-pressure torsion. Journal of Materials Research. 2015;30(18):2804-2815.
27. Sauvage X, Wilde G, Divinski SV, Horita Z, Valiev RZ. Grain boundaries in ultrafine grained materials processed by severe plastic deformation and related phenomena. Materials Science and Engineering: A. 2012;540:1-12.

28. Lu K, Lu L, Suresh S. Strengthening materials by engineering coherent internal boundaries at the nanoscale. Science. 2009;324(5925):349-352.

29. Valiev RZ, Estrin Y, Horita Z, Langdon TG, Zehetbauer MJ, Zhu YT. Producing bulk ultrafine-grained materials by severe plastic deformation: ten years later. JOM. 2016;68(4):12161226.

30. Valiev RZ, Estrin Y, Horita Z, Langdon TG, Zehetbauer MJ, Zhu YT. Fundamentals of superior properties in bulk NanoSPD materials. Materials Research Letters. 2016;4(1):1-21.

31. Oh-ishi K, Edalati K, Kim HS, Hono K, Horita Z. High-pressure torsion for enhanced atomic diffusion and promoting solid-state reactions in the aluminum-copper system. Acta Materialia. 2013;61(9):3482-3489.

32. Qiao X, Li X, Zhang X, Chen Y, Zheng M, Golovin IS, et al. Intermetallics formed at interface of ultrafine grained $\mathrm{Al} / \mathrm{Mg}$ bi-layered disks processed by high pressure torsion at room temperature. Materials Letters. 2016;181:187-190.

33. Bouaziz O, Kim HS, Estrin Y. Architecturing of metal-based composites with concurrent nanostructuring: a new paradigm of materials design. Advanced Engineering Materials. 2013;15(5):336-340.

34. Han JK, Lee HJ, Jang JI, Kawasaki M, Langdon TG. Micromechanical and tribological properties of aluminum-magnesium nanocomposites processed by high-pressure torsion. Materials Science and Engineering: A. 2017;684:318-327.

35. Lu K. The Future of metals. Science. 2010;328(5976):319-320.

36. Ashby MF. Materials Selection in Mechanical Design. $3^{\text {rd }}$ ed. Oxford: Butterworth-Heinemann; 2005.

37. Fang TH, Li WL, Tao NR, Lu K. Revealing extraordinary intrinsic tensile plasticity in gradient nano-grained copper. Science. 2011;331(6024):1587-1590.

38. Wu X, Jiang P, Chen L, Yuan F, Zhu YT. Extraordinary strain hardening by gradient structure. Proceedings of the National Academy of Science of the United States of America. 2014;111(20):7197-7201.

39. Lu K. Making strong nanomaterials ductile with gradients. Science. 2014;345(6203):1455-1456.

40. Wu XL, Jiang P, Chen L, Zhang JF, Yuan FP, Zhu YT. Synergetic strengthening by gradient structure. Materials Research Letters. 2014;2(4):185-191.

41. Kang JY, Kim JG, Park HW, Kim HS. Multiscale architectured materials with composition and grain size gradients manufactured using high-pressure torsion. Scientific Reports. 2016;6:26590.

42. Bouaziz O, Bréchet Y, Embury JD. Heterogeneous and architectured materials: a possible strategy for design of structural materials. Advanced Engineering Materials. 2008;10(1-2):24-36. 